Article

\title{
Model Details, Parametrization, and Accuracy in Daily Scale Green Roof Hydrological Conceptual Simulation
}

\author{
Mirka Mobilia * $\mathbb{D}$ and Antonia Longobardi $\mathbb{D}$ \\ Department of Civil Engineering, University of Salerno, 84084 Salerno, Italy; alongobardi@unisa.it \\ * Correspondence: mmobilia@unisa.it
}

Received: 22 April 2020; Accepted: 28 May 2020; Published: 1 June 2020

\begin{abstract}
In time, several models with different complexity have been proposed to predict the retention performances of a green roof. In the current study three conceptual models of increasing complexity in descriptive details, are calibrated and compared to experimental data. The proposed approaches consist of daily scale hydrological models, based on water balance equations, where the main processes and variables accounted for are the precipitation input, the evapotranspiration losses, and the maximum water storage capacity. Model detail increase is achieved moving from an approach using potential evapotranspiration and constant storage threshold to an approach using actual evapotranspiration and a variable storage threshold. The main findings confirm on one side the role played by evapotranspiration modeling and, on the other side, the good accuracy achieved, in a minimal calibration requirement approach, through the modeling of basic and elemental processes.
\end{abstract}

Keywords: green roofs; hydrological model; water balance; evapotranspiration; Antecedent Precipitation Index model; precipitation

\section{Introduction}

In the relatively recent past, many scientific studies have demonstrated the potential of green roofs (GR) in pursuing the concept of sustainable stormwater management [1-4]. This technology induces important hydraulic benefits compared to a traditional roof, such as a decrease in runoff volume, peak discharge attenuation [5,6], and an increase in the peak delay [7,8]. With reference to the green roof retention properties, different authors have reported significantly different hydrological performances with a reduction of the total volume of precipitation ranging from 40\% to 90\% [9-11]. The retention capacity of a GR is a function of climate conditions but the system configuration also plays an important role [12]. Further complexity arises from the considered particular hydrological processes and especially from the modeled evapotranspiration loss, as discussed in many recent works, as it directly impacts the green roof retention performances [13-16]. Processes schematization into modeling frameworks also plays an important role and it is well known indeed how model complexity affects model performances. Relatively simpler approaches are frequently preferred to over complex ones as low calibration requirements are associated with a more robust parameters estimation [17-19]. In this study, three conceptual retention models, of increasing details complexity, are calibrated and compared, against experimental data. The proposed approaches consist of daily scale GR hydrological conceptual models, based on water balance equations, where the main processes and variables accounted for are the precipitation input, the evapotranspiration losses, and the maximum water storage capacity, herein named storage threshold [20]. The models predict precipitation storages until the maximum soil water holding capacity is reached, then runoff occurs. During the inter-storm period, the GR storage capacity is instead restored by evapotranspiration fluxes. As a common 
feature, the three approaches only require meteorological data for hydrological simulation. An increase in model details description is achieved moving from an approach based on the use of potential evapotranspiration process and a constant storage threshold to an approach with a constant storage threshold but where actual evapotranspiration is considered and then eventually to a modeling scheme where the actual evapotranspiration process and a variable storage threshold are accounted for. The results are threefold. On one side, the crucial role played by the schematization and by the model proposed for evapotranspiration losses formulation is confirmed, as it results in a strong impact on model performances. On the other side, an increase in the model details corresponds to an increase in model accuracy but does not correspond to an increase in model parametrization. Finally, it appears that if interested in long term simulation, as might be in the case of pre-development assessment, green roof model accuracy can be achieved, in a minimal calibration requirement approach, through the modeling of basic and elemental processes.

\section{Experiments}

\subsection{The Study Site and Data}

The case study is an extensive green roof with an area of $22 \mathrm{~m}^{2}$, a slope of about $5^{\circ}$, and a total depth of $20 \mathrm{~cm}$. It is located on the garage of a one-family house in Bernkastel-Kues $\left(49^{\circ} 55^{\prime} 11^{\prime \prime} \mathrm{N}\right.$, $7^{\circ} 4^{\prime} 33^{\prime \prime}$ E, $145 \mathrm{~m}$ above sea level), Rhineland-Palatinate, the western part of Germany (Figure 1a). The roof is made up of three layers: the vegetation layer (spontaneous vegetation), the growing medium (mineral substrate), and a water storage/protective layer (retention Hydrotex membrane) (Figure 1b). The Hydrotex membrane has a thickness of $1 \mathrm{~cm}$, a weight of $850 \mathrm{~g} / \mathrm{m}^{2}$, and a horizontal permeability higher than $2.3 \mathrm{~L} / \mathrm{m} \cdot \mathrm{s}$.

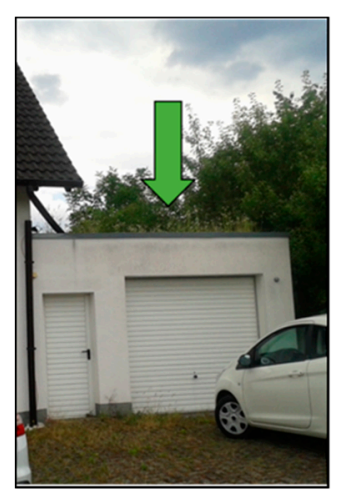

(a)

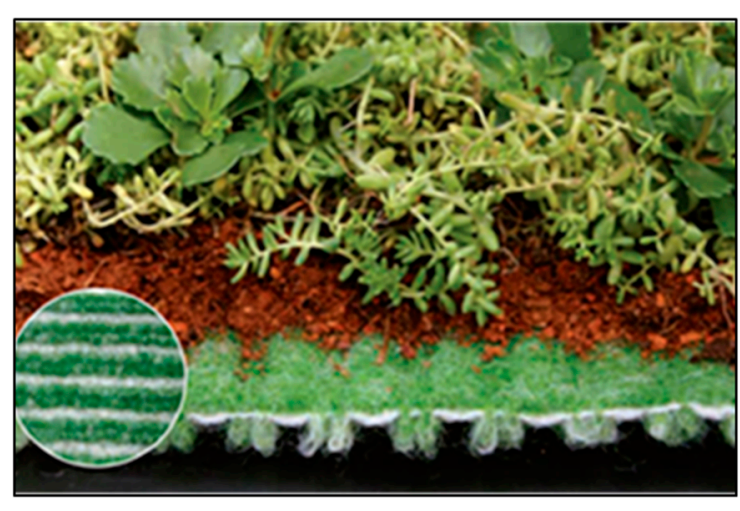

(b)

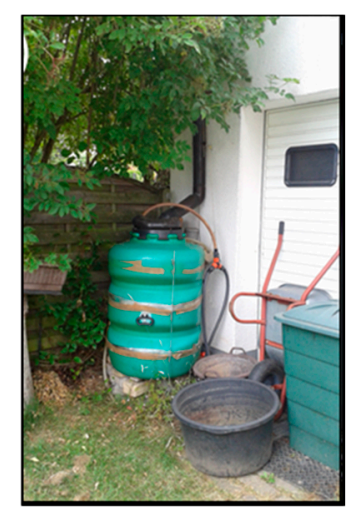

(c)

Figure 1. (a) Green roof location; (b) cross-section of the green roof; (c): Runoff collection tank.

The runoff from the roof is channeled into a $500 \mathrm{~L}$ tank (Figure 1c) where the flow measurement has been performed by reading the actual water level in the reservoir daily. The climate regime is typically oceanic. The average precipitation is about $700-800 \mathrm{~mm} /$ year and it is approximately uniformly distributed during the year. Temperature exhibits instead a typical seasonal pattern, with the highest monthly mean values during the summer season of about $18^{\circ} \mathrm{C}$ and annual average temperature of $9.4^{\circ}$ (Figure 2). The meteorological data used in this work are precipitation recorded at the experimental site and wind speed, air temperature, relative humidity, global radiation collected at the nearest available meteorological station, Bernkastel (AgrarMeteorologie, Rheinland-Pfalz, www.am.rlp.de).

Runoff measurements have been recorded, with a daily time step, from March 2004 to May 2007, but some missing data appear during the monitoring period, preventing the total period of observation to be used for modeling purposes. Generally, no significant runoff has occurred, due to freezing of 
the water, between late December and late March. For this reason, the winter period has not been considered in the simulation approach.

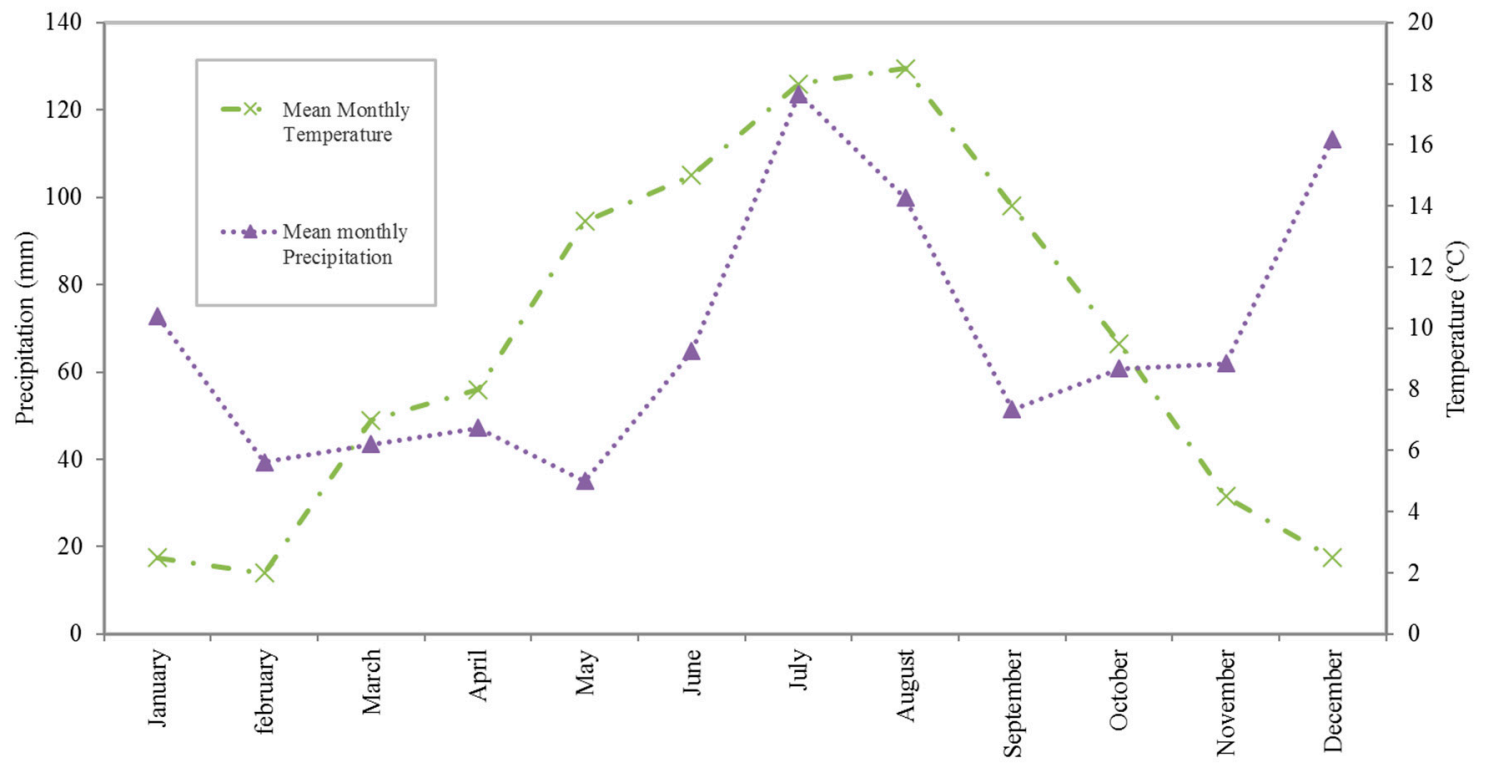

Figure 2. Patterns of long-term mean monthly rain and temperature for the study site.

\subsection{Methodology}

The aim of the reported research is an analysis of the impact of the complexity in the description of variables and processes of a green roof hydrological model on the relative parametrization and accuracy, with a focus on the retention capacity of the green infrastructure. To this purpose, a daily scale conceptual hydrological model is applied, based on water balance equations whose main input variables are the precipitation, the evapotranspiration loss, and the maximum water storage capacity, here called the storage threshold [20]. The model is used with three different settings $(\bmod A, \bmod B$, and mod C), characterized by increasing complexity in the description of the involved variables and processes (Table 1).

Table 1. Models settings for different model complexity level. Mod A represents the basic approach. Mod B represents the intermediate approach. Mod C represents the detailed approach. (ET: Evapotranspiration, PET: Potential Evapotranspiration, AET: Actual evapotranspiration, $W_{\max }$ : Maximum water holding capacity)

\begin{tabular}{ccc}
\hline Method & ET & $\boldsymbol{W}_{\max }$ \\
\hline mod A & PET & Constant \\
$\bmod B$ & AET & Constant \\
$\bmod C$ & AET & Variable \\
\hline
\end{tabular}

The three settings correspond to a basic approach based on the use of potential evapotranspiration and a constant storage threshold $(\bmod \mathrm{A})$; an intermediate approach where actual evapotranspiration and a constant storage threshold are accounted $(\bmod B)$; a detailed approach where actual evapotranspiration and a variable maximum water holding depth are used (mod C). The three conceptual retention models, of different complexity, are calibrated using the values of runoff recorded at the presented experimental site. 


\subsubsection{The Governing Equations}

The water balance equations used to simulate the runoff production " $R$ ", common to all of the three model settings, are [20]

$$
\left\{\begin{array}{c}
V_{t}=V_{t-1}+P_{t}-\mathrm{ET}_{t} \leq W_{\max } \rightarrow R_{t}=0 \\
V_{t}=V_{t-1}+P_{t}-\mathrm{ET}_{t}>W_{\max } \rightarrow R_{t}=V_{t}-W_{\max }=V_{t-1}+P_{t}-\mathrm{ET}_{t}-W_{\max }
\end{array}\right.
$$

where " $t$ " is the daily time index, " $V$ " the green roof water depth, " $P$ " the observed precipitation, "ET" the modeled evapotranspiration loss, " $W_{\max }$ " the maximum water-holding depth or storage threshold.

In the basic approach, ET loss is assumed to be set on the potential evapotranspiration (PET) and a constant storage threshold is also considered. The governing equations become

$$
\left\{\begin{array}{c}
V_{t}=V_{t-1}+P_{t}-\mathrm{PET}_{t} \leq W_{\text {max }} \rightarrow R_{t}=0 \\
V_{t}=V_{t-1}+P_{t}-\mathrm{PET}_{t}>W_{\text {max }} \rightarrow R_{t}=V_{t}-W_{\text {max }}=V_{t-1}+P_{t}-\mathrm{PET}_{t}-W_{\text {max }}
\end{array}\right.
$$

where the term " $\mathrm{ET}_{t}$ " is replaced by "PET $t$ ". As PET is rapidly computed form meteorological observation, $W_{\max }$ represents the only model parameter to be calibrated.

Potential evapotranspiration represents an ideal process but for a better model performance, the actual evapotranspiration process should be modeled. Actual evapotranspiration AET modeling generally requires soil moisture, and soil and vegetation properties data. In the following, to keep to a minimum the number of needed information, an approach simply based on meteorological variables is used. The proposed model is based on the concept of the non-potential Priestley-Taylor model [21]. In the intermediate approach, ET loss is then assumed to be set on the non-potential Priestley-Taylor evapotranspiration (AET) and a constant storage threshold is accounted for. The governing equations are represented by Equation (3) where the term " $\mathrm{ET}_{t}$ " is replaced by " $\mathrm{AET}_{t}$ ":

$$
\left\{\begin{array}{c}
V_{t}=V_{t-1}+P_{t}-\mathrm{AET}_{t} \leq W_{\text {max }} \rightarrow R_{t}=0 \\
V_{t}=V_{t-1}+P_{t}-\mathrm{AET}_{t}>W_{\text {max }} \rightarrow R_{t}=V_{t}-W_{\text {max }}=V_{t-1}+P_{t}-\mathrm{AET}_{t}-W_{\text {max }}
\end{array}\right.
$$

As in the case of the basic model, in mod B of Table $1 W_{\max }$ represents the only parameter to be calibrated for hydrological simulation. Considered as the amount of water stored between the permanent wilting point and the field capacity, the maximum water holding capacity $W_{\max }$ depends on substrate layer material properties and represents a constant physical threshold. The constant physical limit could be however called into the discussion, if it is considered that due soil heterogeneity runoff can occur even before the actual capacity is reached and that vegetation provides some additional moisture storage capacity to be accounted for [13]. $W_{\max }$ is more likely to represent a process rather than a physical property and, as exhaustively discussed in [20], a strong correlation is found between the water holding capacity $W_{\max }$ and the stored depth $V$, in that it can be assumed that

$$
W_{\text {max }, t} \approx V_{t-1}
$$

According to such discussion, in the mod C of Table 1, ET loss is assumed to be set on the actual evapotranspiration (AET) and a variable storage threshold is accounted for " $W_{\text {max }, t}$ " and "AET $t$," respectively, replace " $W_{\max }$ " and " $\mathrm{ET}_{t}$ " in Equation (1) and the water balance equations are

$$
\left\{\begin{array}{c}
V_{t}=V_{t-1}+P_{t}-\mathrm{AET}_{t} \leq W_{\max , t} \rightarrow R_{t}=0 \\
V_{t}=V_{t-1}+P_{t}-\mathrm{AET}_{t}>W_{\text {max }, t} \rightarrow R_{t}=V_{t}-W_{\text {max }, t}=\left(V_{t-1}+P_{t}-\mathrm{AET}_{t}\right)-W_{\text {max }, t}
\end{array}\right.
$$

where the second equation, according to Equation (4), can be rewritten as

$$
R_{t}=V_{t}-W_{m a x, t}=V_{t}-V_{t-1}=\left(V_{t-1}+P_{t}-\mathrm{AET}_{t}\right)-V_{t-1}=P_{t}-\mathrm{AET}_{t}
$$


Model details are more complex, as more processes are schematized, but contrary to what was expected, model parametrization is lessened, as no parameter has to be calibrated for simulation purposes.

\subsubsection{Models Selection for Potential and Actual Evapotranspiration Assessment}

Within the study area, there are no instruments to directly measure ET fluxes such as eddy covariance stations, chambers, sap flow systems, and weighing lysimeters. Due to the lack of observational flux data, a weighted and careful selection of the most accurate methods for the indirect ET modeling has not been possible and Penman formulation [22] has been considered for PET modeling while the API model [23] has been used to reproduce AET. According to the literature, the Penman model is one of the most commonly used methods for the assessment of PET in in-the-field research [24] so it has been chosen as it represents a well-consolidated approach. With regards to the API approach, even if less recent, this model has proven to perform well in similar studies where it has been compared with other ET methods including the AA (advection aridity) model [20,25].

The Penman Equation [22] can be expressed as

$$
\operatorname{PET}_{P}=\frac{1}{\lambda}\left[\frac{\Delta}{\Delta+\gamma}\left(R_{n}-G_{\text {soil }}\right)\right]+\left[\frac{\gamma}{\gamma+\Delta} E_{A}\right]
$$

where $\lambda\left(\mathrm{MJ} \mathrm{kg}^{-1}\right)$ is the latent heat of vaporization:

$$
\lambda=2.501-\left(2.361 \times 10^{-3}\right) T
$$

$T$ is the air temperature $\left({ }^{\circ} \mathrm{C}\right), R_{n}\left(\mathrm{MJ} \mathrm{m}^{-2}\right.$ day $\left.^{-1}\right)$ is the net radiation, $G_{\text {soil }}\left(\mathrm{MJ} \mathrm{m}^{-2}\right.$ day $\left.^{-1}\right)$ is the soil heat flux considered to be negligible on a daily time scale [26], $\Delta\left(\mathrm{kPa}^{\circ} \mathrm{C}^{-1}\right)$ is the slope of the saturation vapor pressure-temperature relationship:

$$
\Delta=\frac{4098 e_{s}}{(T+237.3)^{2}}
$$

$e_{S}$ is the saturation vapor pressure:

$$
\mathrm{e}_{\mathrm{s}}=0.611 \exp \left(\frac{17.27 \cdot \mathrm{T}}{\mathrm{T}+237.3}\right)
$$

$\gamma$ is the psychrometric constant $\left(\mathrm{kPa}^{\circ} \mathrm{C}^{-1}\right)$, and $E_{A}$ is the drying power of the air expressed as

$$
E_{A}=2.6\left(1+0.54 u_{2}\right)\left(e_{s}-e_{a}\right)
$$

$u$ is the wind speed $\left(\mathrm{ms}^{-1}\right), e_{a}$ is the vapor pressure $(\mathrm{kPa})$.

Indirect estimation for actual evapotranspiration modeling is here proposed through the case of empirical relation that, opposite to more physically based methods, are simply based on routinely measured meteorological variables. Among these, methods with a firm physical analysis have been applied, in the past, based on the non-potential evapotranspiration concept by Priestley and Taylor $[21,27,28]$. The API (Antecedent Precipitation Index) approach models actual evapotranspiration modifying the potential evapotranspiration suggested by Priestley-Taylor with a coefficient $\alpha$ depending on the API [23] and representing the soil moisture content:

$$
A E T_{A P I}=0.408 \cdot \alpha\left[\frac{\Delta}{\Delta+\gamma}\left(R_{n}-G\right)\right]
$$


where $\alpha(-)$ is:

$$
\left\{\begin{array}{c}
\alpha=0.123(A P I)-0.0029(A P I)^{2}-0.0000056(A P I)^{3} \quad \text { if } A P I \leq 20 \mathrm{~mm} \\
\alpha=1.26 \text { if } A P I>20 \mathrm{~mm}
\end{array}\right.
$$

In Figure 3, the monthly patterns of potential, actual evapotranspiration, temperature and precipitation from April 2005 to December 2006 are shown. Potential fluxes approach actual during the cold and wet period from November to December.

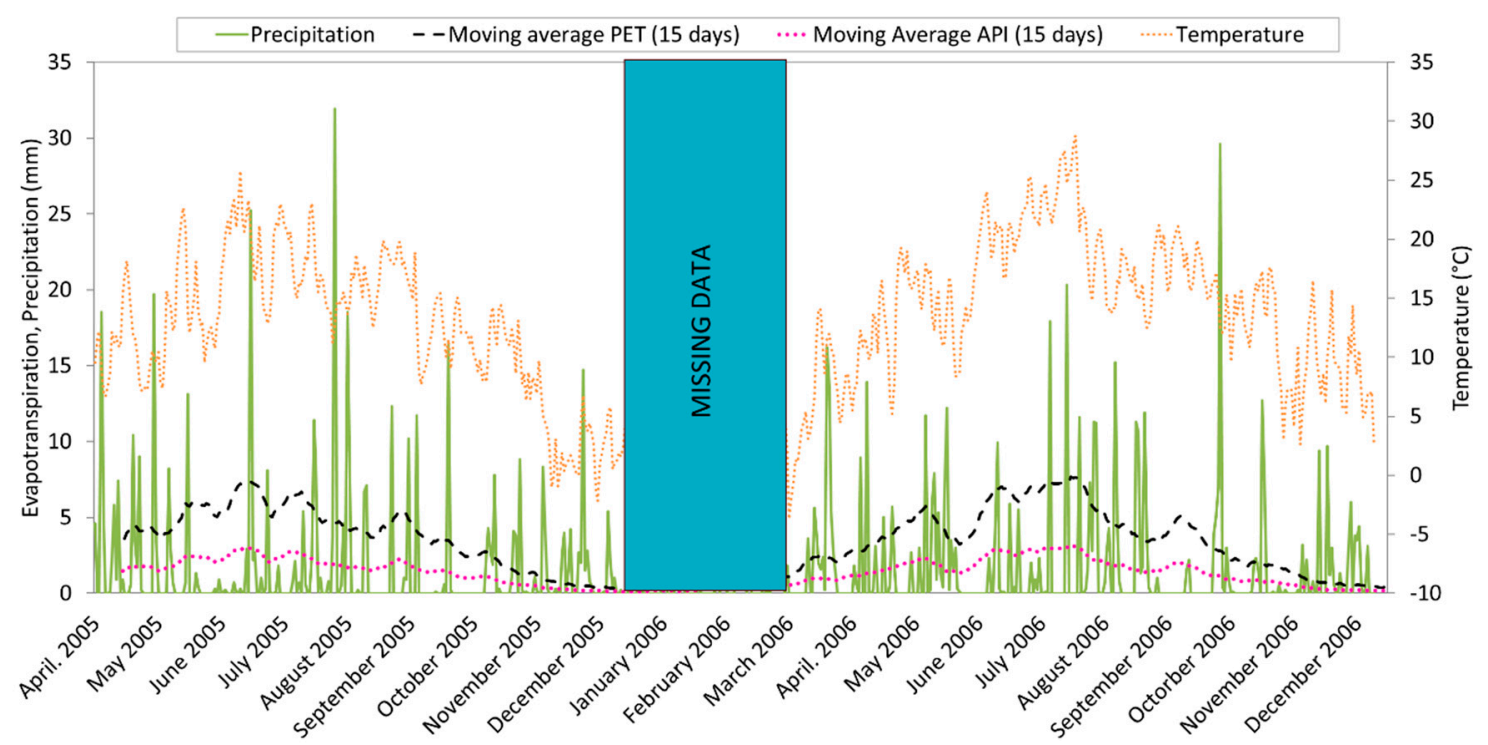

Figure 3. Daily patterns of potential evapotranspiration (PET), actual evapotranspiration (AET), temperature and precipitation during the period of observation.

\section{Results}

In the case of mod A and mod B settings, evapotranspiration losses, respectively potential and actual fluxes, represent functions of meteorological variables. They can be assessed a priori and used as a climate forcing for the GR model, not dependent on the stored water depth $V$. Mod A and mod B hydrological simulations rely thus only on $W_{\max }$ calibration. In the case of $\bmod C$, as previously discussed $W_{\max }$ is assumed to change during the simulation. This circumstance, as discussed, causes a simplification of the water balance equation, and the hydrological simulation does not require a calibration phase, with runoff production modeled as in Equation (6).

\subsection{Models Evaluation}

In the case of mod $A$ and mod $B, W_{\max }$ calibration is achieved assuming that total modeled runoff equals total observed runoff, for each period of simulation. This assumption, even though it appears simplified, allows us to streamline the calibration process and to reduce the computational efforts required by the models. In addition, because of missing observational data due to the temporary failure of the monitoring system, the event scale calibration is difficult to achieve. Such a calibration of the models allows one to obtain an accurate assessment of the long-term hydrological performances of the green roof at the cost of a less effective prediction of the runoff at finer scales. Results are illustrated in Figures 4 and 5. At first visual inspection, in the case of mod A and mod B, several runoff events are not modeled and in most cases, an overestimation occurs. Mod $C$ appears the best performing among the three different considered model settings. To quantitatively judge the ability of the approaches to reproduce the observed runoff, two fit indices, an average of absolute percentage errors (AAPE), root-mean-square errors (RMSE), and the percentage RMSE have been calculated: 


$$
\begin{gathered}
A A P E=\frac{1}{n} \sum_{i=1}^{n}\left|\frac{R_{o b s, i}-R_{m o d, i}}{R_{o b s, i}}\right| \\
R M S E=\frac{1}{n}\left[\sum_{i=1}^{n}\left(R_{m o d, i}-R_{o b s, i}\right)^{2}\right]^{\frac{1}{2}} \\
R M S E(\%)=\frac{R M S E}{\overline{R_{o b s}}} * 100
\end{gathered}
$$

with " $n$ " the number of points of discontinuity of the cumulated runoff distribution (e.g., runoff events occurrences in Figure 5) where the fit is evaluated, $R_{\text {mod }}$ is the modeled runoff, $R_{o b s}$ the observed runoff, and $\overline{R_{o b s}}$ the total average observed runoff. The results are illustrated in Table 2.
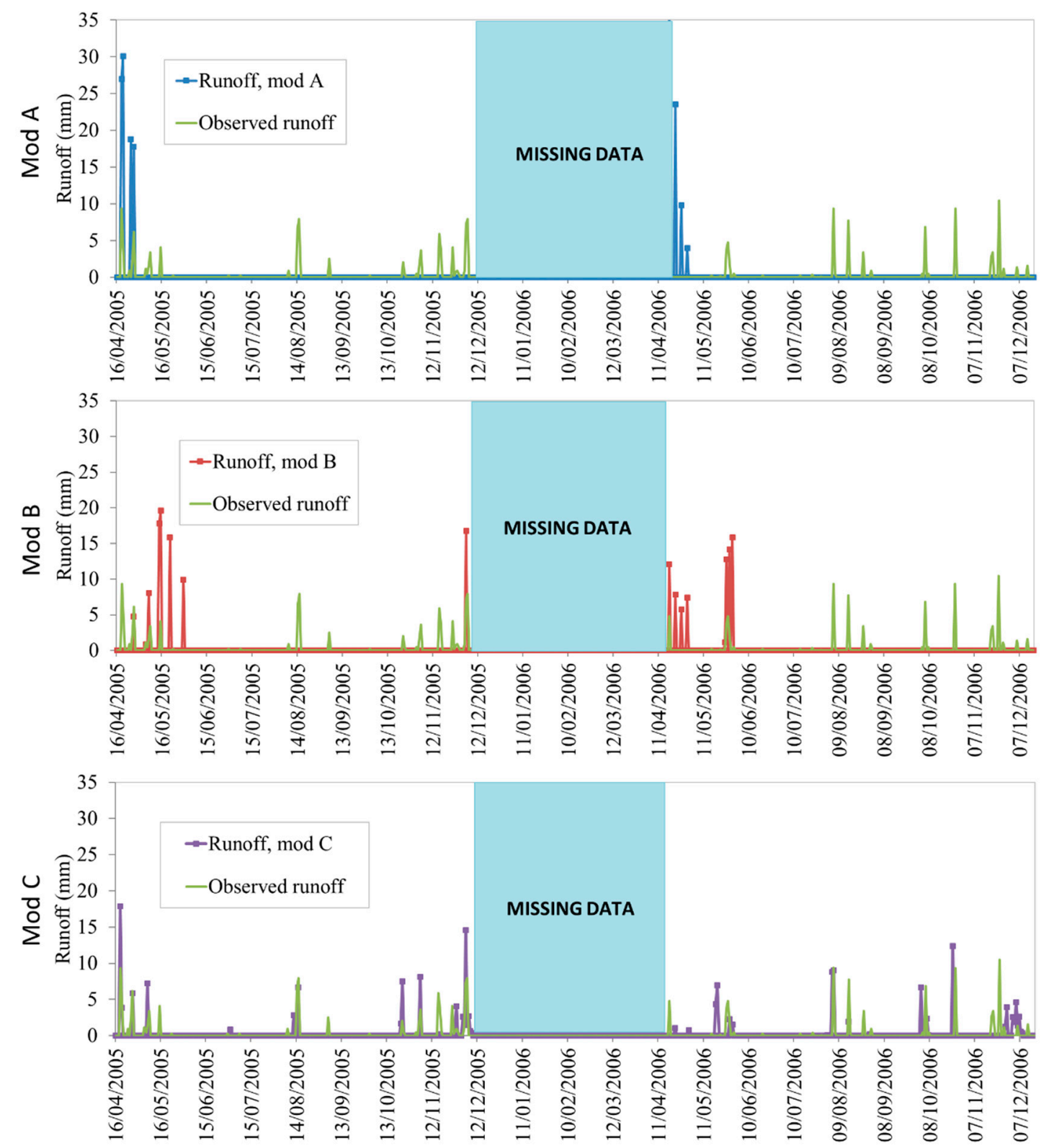

Figure 4. Comparison between modeled and observed runoff time series for the different approaches. 
(a)

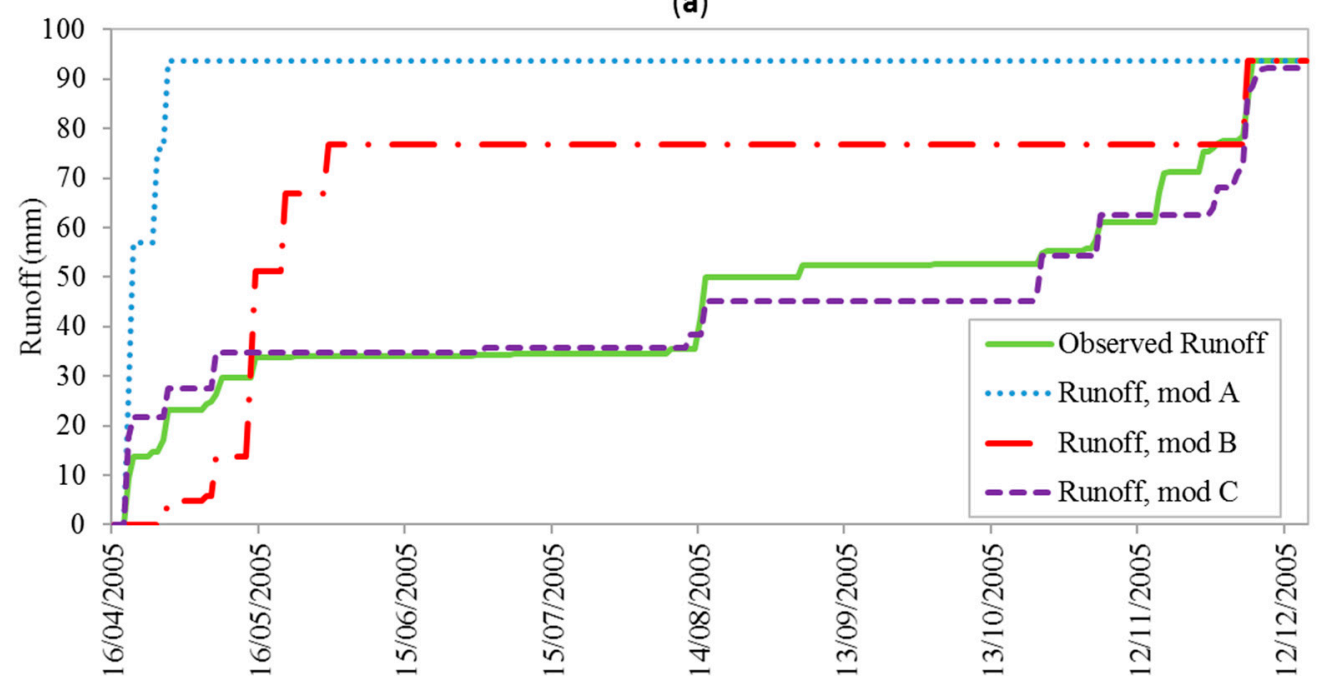

(b)

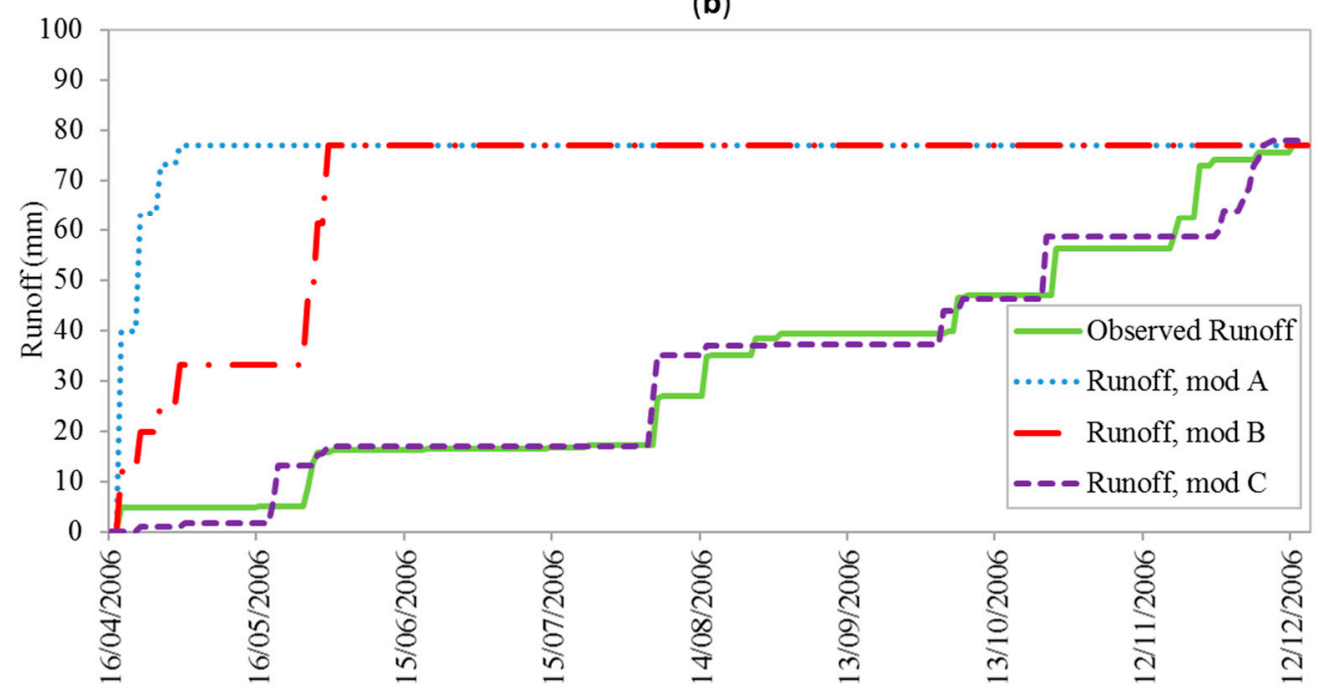

Figure 5. Comparison between cumulated observed runoff from the studied green roof and cumulated runoff modeled using the three approaches with increasing level of complexity. (a) simulated period: 2005. (b) simulated period: 2006.

Table 2. Values of the root-mean-square errors (RMSE) and absolute percentage errors (AAPE) for the different approaches.

\begin{tabular}{ccccc}
\hline Year & Method & $\boldsymbol{R}_{\text {mod }}(\mathbf{m m})$ & RMSE $(\mathbf{m m})$ & AAPE $(\%)$ \\
\hline \multirow{2}{*}{$2005 \mathrm{R}_{\text {obs }}(\mathrm{mm})=93.6$} & $\bmod A$ & 93.64 & 13.15 & 126.40 \\
& $\bmod B$ & 93.64 & 5.83 & 48.17 \\
& $\bmod C$ & 92.34 & 1.75 & 13.08 \\
$2006 \mathrm{R}_{\text {obs }}(\mathrm{mm})=77.0$ & $\bmod A$ & 77.05 & 146.50 & 9.79 \\
& $\bmod B$ & 77.05 & 89.87 & 8.71 \\
& $\bmod C$ & 77.91 & 15.64 & 1.53 \\
\hline
\end{tabular}

Although a calibration process has been performed and cumulative simulated runoff equals the observed one, mod A, regardless for the modeled period, is characterized by the largest errors, with RMSE (\%) above 14\% (in 2005), of average observed runoff, and AAPE approaching $126 \%$ (in 2005). Cumulative modeled runoff pattern significantly differs from the observed one and it is practically not at all affected from rainfall occurrences, as the cumulative runoff, for the total period of observation, is approached in the earlier period of the simulation (Figure 5). Moving from potential to actual 
evapotranspiration losses increases model accuracy. RMSE (\%) and AAPE values for mod B are indeed lower than in the case of mod A, respectively equal to about $11 \%$ and $89 \%$ (in 2006), but cumulative simulated runoff pattern is still significantly different from the observed one. A larger sensitivity to rainfall occurrences is detected however compared to mod A (Figure 5). Despite the lack of a calibration process, mod $C$ appears to be the best performing method also from a quantitative point of view. RMSE (\%) and AAPE indices approach the lowest values of about $2 \%$ and $15 \%$ (for both years) respectively. Furthermore, a cumulated modeled pattern is very close to the observed one and total cumulated runoff only differs from about $1 \%$ from observed one (Figure 5). Calibrated values for the maximum water holding capacities for mod A and mod B are illustrated in Table 3 as a percentage of total soil depth.

Table 3. Calibrated (mod A and mod B) maximum water holding capacities as a percentage of total soil depth.

\begin{tabular}{ccc}
\hline Year & Mod A (\%) & Mod B (\%) \\
\hline 2005 & 26.6 & 46.1 \\
2006 & 24.3 & 38.9 \\
\hline
\end{tabular}

The values assumed by the calibrated $W_{\max }$ for both models and years can be discussed with reference to the cumulative evapotranspiration losses for each model and for each year. According to Equation (1), $W_{\max }$, which in the presented study does not represent a physical property, is called to balance the evapotranspiration losses in the hydrological model. Provided an observed amount of precipitation $P$ and provided the calibration rule that is the cumulate observed runoff equal to the cumulated modeled runoff, larger ET losses are to be balanced by lower $W_{\max }$ values. Comparing the $W_{\max }$ values (for both years) for mod A and mod B, it can be observed that they are larger in the case of mod B, being the ET losses in the mod B schematized as the AET, lower than the PET accounted in mod A. The same justification can be provided for the difference in the $W_{\max }$ values that for both models can be observed between the year 2005 and 2006. In the year 2006, the PET losses have been only 1\% larger than PET losses in 2005. The difference in AET between the two years has been instead of about $6 \%$. $W_{\max }$ are then lower in 2006 compared to 2005 values to balance the larger ET losses in 2006 compared with the 2005 ET losses. Differences between 2005 and $2006 W_{\max }$ are negligible in the case of mod A (about $8 \%$ ) which considers PET and very moderate in the case of mod B (about 15\%) which considers the AET.

\subsection{Impact of Maximum Water Holding Capacity Threshold}

In the case of mod A and mod B the hydrological simulations require calibration for the water holding capacity threshold $W_{\max }$. For such approaches it would be important, especially in the context where experimental data are not available for calibration, to study the impact of the choice for a particular value of $W_{\max }$ on model accuracy. To this purpose, a sensitivity analysis has been performed, in the case of mod A and mod $\mathrm{B}$, to measure model performances through RMSE and AAPE statistical indices. The results are illustrated in Figure 6. For both cases, RMSE and AAPE illustrate how, as a result of the calibration, errors monotonically increase for $W_{\max }$ values lower than the calibrated threshold. In the case of mod A, for a given $W_{\max }$ value, errors occurring in 2005 and 2006 are different probably because the different cumulated runoff rates (Table 2) for the two periods are not balanced by instead very similar potential evapotranspiration cumulate loss for the same time intervals. The largest errors are indeed predicted for the 2005 period, characterized by the largest potential evapotranspiration loss. On the contrary, in the case of mod B, errors occurring in 2005 and 2006 are almost similar, probably because the different cumulated runoff rates (Table 2) for the two periods are balanced by a different actual evapotranspiration cumulate loss for the same time intervals. Model errors associated with mod B are compared to mod A, larger, for $W_{\max }$ different from the calibrated threshold. Such circumstance indicates a larger sensitivity of mod B to uncalibrated $W_{\max }$ compared to what occurs for 
mod A. Lower evapotranspiration losses (by an actual process as formulated in mod B) correspond to lower rainwater storage availability and thus, for a given $W_{\max }$, to larger runoff rates and larger overestimation (Figure 4).
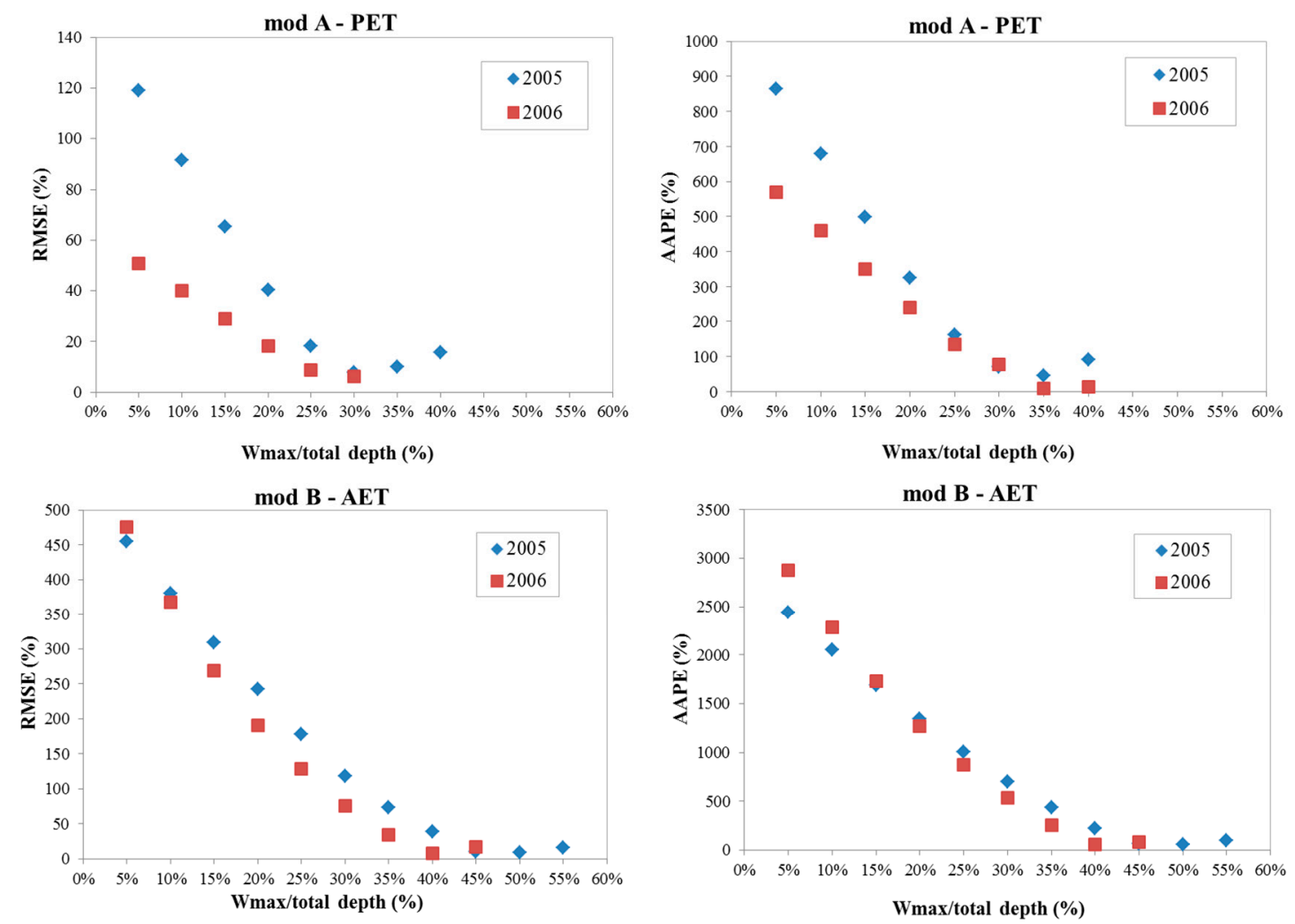

Figure 6. Impact of water holding capacity (as a percentage of soil total depth) for mod A (upper panel) and mod B (lower panel) on RMSE and AAPE values.

\section{Discussion and Conclusions}

The present paper has presented a comparison of model performances, accuracies, and parametrization for three different hydrological green roof conceptual models aimed at the assessment of the green roof retention capacity. As a common feature, only meteorological data are needed for hydrological simulation for all of the proposed approaches. The three proposed models differ for the complexity of details in the formulation and schematization of the considered hydrological processes, from a basic $(\bmod A)$ to an intermediate $(\bmod B)$ to a more detailed approach $(\bmod C)$. Mod A needs a little computational effort and technical expertise. It implements the potential evapotranspiration concept and it requires only basic meteorological input data which can be readily derived by publicly available databases. In mod A, a calibration process is performed through the comparison between the total modeled and measured runoff during the period of observation. Similar to the previous model, mod B carries out a calibration procedure of the storage threshold which is assumed constant but, on the other side, it requires the calculation of the actual evapotranspiration rates. Mod C sets ET on AET and considers a variable threshold as it represents a process rather than a physical property. So, this model embeds more detailed processes into hydrological modeling. Mod A is a basic approach and consequently, it is not able to predict the runoff production at event scale but is sufficient if the model user is interested in long term analysis of green roof potential runoff reduction and it can predict the total amount of runoff, in the long term, with a good degree of accuracy and with a relatively important sensitivity to model parameter calibration. The transition from mod A to mod B implies the increase in the prediction accuracy, but despite this, the model is mainly recommended for long term analysis of GR response. If interested in reproducing the behavior of the green system at a finer 
scale, model $C$ can be used. Indeed, a more detailed model description has the benefit of improved model accuracy, as shown by the comparison of the computed statistical indices. This latter model can effectively simulate both the long-term green roof behavior and the daily scale GR performance. The correct assessment of both long term and single event GR hydrological response is crucial to identify the benefits of this green infrastructure in urban areas. Knowing the hydrological behavior at a finer scale allows one to quantify the rainfall attenuation during individual storms to face flooding events occurring in urban areas and to achieve sustainable urban drainage management. However, the long-term assessment of green roof hydrological performances is likewise essential. It provides an effective tool for practitioners, regulators, and engineers to make more informed decisions about GR implementation within urban areas. The economic benefits, at the hydrological level, of installing green roofs cannot be detectable immediately but in the long term indeed. A cost-benefit analysis, which is fundamental to justify the economic costs associated with green roofs, including the cost of installation and maintenance over time, would undoubtedly benefit from additionally account for the environmental benefits.

The findings of the present work are supported by several studies present in the scientific literature. Indeed, over time, many authors [19,29] compared hydrological models with different complexity to identify the best performing one for the assessment of GR hydrological performances. In [19], the accuracy of Storm Water management model (SWMM), Hydrus and Nash models in predicting the response of green roof to rainfall events have been compared. In terms of required input parameters and hydrological processes simulated in the model, the Nash approach results in the less complex method followed by Hydrus and SWMM. The RMSE decreases when switching from the less detailed model to the most detailed one. In particular, the Nash model is featured by an RMSE of $0.36 \mathrm{~mm}$, Hydrus presents an error value of about $0.29 \mathrm{~mm}$ and SWMM returns an RMSE of about $0.28 \mathrm{~mm}$. Similar results come out from [29], where a comparative study which refers to rainfall-runoff modeling, between SWMM and Fuzzy Logic Approach has been proposed. The fuzzy logic model outperforms the SWMM returning lower errors. In detail, RMSE is $3.31 \mathrm{~mm}$ for SWMM and $2.44 \mathrm{~mm}$ for the Fuzzy Logic Model. In [30] a comparison, in terms of Nash-Sutcliffe efficiency index (NSE), between a linear reservoir model and Hydrus has been set up with the result that the mechanistic model, which uses more details in the description of hydrological processes, returns higher performances than the conceptual approach. The average NSE is 0.87 for Hydrus and 0.70 for the reservoir model. Other authors [31] compared complex approaches able to model Low Impact Development (LID) practices incorporated within the drainage network with the finite element model with the results that generally the first outperforms the second ones. In this case, the first kind of model exhibits a value of NSE of 0.88 against 0.79 of the finite element model for events with rainfall intensity of $1.5 \mathrm{~mm} / \mathrm{min}$ and $0.81 \mathrm{~mm}$ against 0.76 for storms with the intensity of $2 \mathrm{~mm} / \mathrm{min}$. These researches confirm what demonstrated in the current work namely that, the model accuracy increases with the details in model description, indeed, moving from the mod A to mod B to mod C, the errors assume the values of 13.15, 5.83, and $1.75 \mathrm{~mm}$ for 2005 and 146.30, 89.87, and $15.64 \mathrm{~mm}$ for 2006.

Author Contributions: Conceptualization, A.L.; Methodology, A.L.; Validation, M.M.; Formal analysis, M.M.; investigation, A.L. and M.M.; Data curation, M.M.; Writing—original draft preparation, A.L. and M.M.; Writing-review and editing, A.L. and M.M.; Supervision, A.L. All authors have read and agreed to the published version of the manuscript.

Funding: This research received no external funding.

Acknowledgments: Authors express their sincere gratitude to Joachim Sartor (Trier University of Applied Sciences) for providing runoff data from the experimental green roof and for his helpful suggestions and guidance during the research.

Conflicts of Interest: The authors declare no conflict of interest. 


\section{References}

1. Cettner, A.; Ashley, R.; Hedström, A.; Viklander, M. Sustainable development and urban stormwater practice. Urban Water J. 2013, 11, 185-197. [CrossRef]

2. Shaharuddin, A.; Noorazuan, M.H.; Yaakob, M.J. Green roofs as best management practices for heat reduction and stormwater flow mitigation. World Appl. Sci. J. 2011, 13, 58-62.

3. Sartor, J.; Mobilia, M.; Longobardi, A. Results and findings from 15 years of sustainable urban storm water management. Int. J. Saf. Secur. Eng. 2018, 8, 505-514. [CrossRef]

4. Mobilia, M.; Longobardi, A. Smart stormwater management in urban areas by roofs greening. Lect. Notes Comput. Sci. 2017, 10406, 455-463. [CrossRef]

5. Versini, P.-A.; Jouve, P.; Ramier, D.; Berthier, E.; De Gouvello, B. Use of green roofs to solve storm water issues at the basin scale-Study in the Hauts-de-Seine County (France). Urban Water J. 2015, 13, 372-381. [CrossRef]

6. Krasnogorskaya, N.; Longobardi, A.; Mobilia, M.; Khasanova, L.F.; Shchelchkova, A.I. Hydrological modeling of green roofs runoff by Nash cascade model. Open Civ. Eng. J. 2019, 13, 163-171. [CrossRef]

7. Gibler, M.R. Comprehensive benefits of green roofs. In Proceedings of the World Environmental and Water Resources Congress 2015: Floods, Droughts, and Ecosystems, Austin, TX, USA, 17-21 May 2015; pp. 2244-2251.

8. Stovin, V.; Vesuviano, G.; De-Ville, S. Defining green roof detention performance. Urban Water J. 2015, 14, 1-15. [CrossRef]

9. Mentens, J.; Raes, D.; Hermy, M. Green roofs as a tool for solving the rainwater runoff problem in the urbanized 21st century? Landsc. Urban Plan. 2006, 77, 217-226. [CrossRef]

10. Teemusk, A.; Mander, Ü. Rainwater runoff quantity and quality performance from a greenroof: The effects of short-term events. Ecol. Eng. 2007, 30, 271-277. [CrossRef]

11. Longobardi, A.; D'Ambrosio, R.; Mobilia, M. Predicting stormwater retention capacity of green roofs: An experimental study of the roles of climate, substrate soil moisture, and drainage layer properties. Sustainability 2019, 11, 6956. [CrossRef]

12. Stovin, V.; Vesuviano, G.; Kasmin, H. The hydrological performance of a green roof test bed under UK climatic conditions. J. Hydrol. 2012, 414, 148-161. [CrossRef]

13. Poë, S.; Stovin, V.; Berretta, C. Parameters influencing the regeneration of a green roof's retention capacity via evapotranspiration. J. Hydrol. 2015, 523, 356-367. [CrossRef]

14. Starry, O.; Lea-Cox, J.; Ristvey, A.; Cohan, S. Parameterizing a water-balance model for predicting stormwater runoff from green roofs. J. Hydrol. Eng. 2016, 21, 04016046. [CrossRef]

15. Feitosa, R.C.; Wilkinson, S.J. Modelling green roof stormwater response for different soil depths. Landsc. Urban Plan. 2016, 153, 170-179. [CrossRef]

16. Voyde, E.; Fassman, E.; Simcock, R.; Wells, J.; Fassman-Beck, E. Quantifying evapotranspiration rates for new zealand green roofs. J. Hydrol. Eng. 2010, 15, 395-403. [CrossRef]

17. Burszta-Adamiak, E.; Mrowiec, M. Modelling of green roofs' hydrologic performance using EPA's SWMM. Water Sci. Technol. 2013, 68, 36-42. [CrossRef]

18. Carson, T.; Keeley, M.; Marasco, D.E.; McGillis, W.; Culligan, P. Assessing methods for predicting green roof rainfall capture: A comparison between full-scale observations and four hydrologic models. Urban Water J. 2015, 14, 589-603. [CrossRef]

19. Mobilia, M.; Longobardi, A. Impact of rainfall properties on the performance of hydrological models for green roofs simulation. Water Sci. Technol. 2020. [CrossRef]

20. Mobilia, M.; Longobardi, A.; Sartor, J.F. Including a-priori assessment of actual evapotranspiration for green roof daily scale hydrological modelling. Water 2017, 9, 72. [CrossRef]

21. Mawdsley, J.A.; Ali, M.F. Estimating nonpotential evapotranspiration by means of the equilibrium evaporation concept. Water Resour. Res. 1985, 21, 383-391. [CrossRef]

22. Penman, H.L. Natural evaporation from open water, bare soil and grass, proceedings of the royal society of London. Ser. Math. Phys. Eng. Sci. 1948, 193, 120-145.

23. Linsley, R.K.; Kohler, M.A. Variations in storm rainfall over small areas. Trans. Am. Geophys. Union 1951, 32, 245. [CrossRef]

24. Bogawski, P.; Bednorz, E. Comparison and validation of selected evapotranspiration models for conditions in Poland (Central Europe). Water Resour. Manag. 2014, 28, 5021-5038. [CrossRef] 
25. Marasco, D.E.; Culligan, P.J.; McGillis, W.R. Evaluation of common evapotranspiration models based on measurements from two extensive green roofs in New York City. Ecol. Eng. 2015, 84, 451-462. [CrossRef]

26. Purdy, A.J.; Fisher, J.B.; Goulden, M.L.; Famiglietti, J. Ground heat flux: An analytical review of 6 models evaluated at 88 sites and globally. J. Geophys. Res. Biogeosci. 2016, 121, 3045-3059. [CrossRef]

27. Priestley, C.H.B.; Taylor, R.J. On the assessment of surface heat flux and evaporation using large-scale parameters. Mon. Weather Rev. 1972, 100, 81-92. [CrossRef]

28. Davies, J.A.; Allen, C.D. Equilibrium, potential and actual evaporation from cropped surfaces in Southern Ontario. J. Appl. Meteorol. 1973, 12, 649-657. [CrossRef]

29. Wang, K.-H.; Altunkaynak, A. Comparative case study of rainfall-runoff modeling between SWMM and fuzzy logic approach. J. Hydrol. Eng. 2012, 17, 283-291. [CrossRef]

30. Palla, A.; Gnecco, I.; Lanza, L.G. Compared performance of a conceptual and a mechanistic hydrologic models of a green roof. Hydrol. Process. 2011, 26, 73-84. [CrossRef]

31. Haowen, X.; Yawen, W.; Luping, W.; Weilin, L.; Wenqi, Z.; Hong, Z.; Yichen, Y.; Jun, L. Comparing simulations of green roof hydrological processes by SWMM and HYDRUS-1D. Water Supply 2019, 20, 130-139. [CrossRef]

(C) 2020 by the authors. Licensee MDPI, Basel, Switzerland. This article is an open access article distributed under the terms and conditions of the Creative Commons Attribution (CC BY) license (http://creativecommons.org/licenses/by/4.0/). 